\title{
Analysis of The Cancer Genome Atlas data to determine the correlation between AGO2, TERT, and TERC in various cancers
}

\author{
Soo-Jung Jung, Jae-Ho Lee \\ Department of Anatomy, Keimyung University School of Medicine, Daegu, Republic of Korea \\ Correspondence to: Jae-Ho Lee. Department of Anatomy, Keimyung University School of Medicine, 2800, Dalgubeoldaero, Dalseo-Gu, Daegu, \\ Republic of Korea. Email: anato82@dsmc.or.kr.
}

Submitted Mar 12, 2019. Accepted for publication Sep 19, 2019.

doi: $10.21037 /$ tcr.2019.09.41

View this article at: http://dx.doi.org/10.21037/tcr.2019.09.41

We read with great interest the article by Laudadio et al. (1) regarding the role of AGO2 in telomere biology; their study asserted that $\mathrm{AGO} 2$ regulated telomerase activity through the control of the association between TERT and TERC in the assembly of active telomerase ribonucleoprotein. They also demonstrated that AGO2 interacted with TERC and with a newly identified sRNA (terc-sRNA), arising from the H/ACA box of TERC. Interestingly, terc-sRNA is significantly overexpressed in breast, lung, and other cancers. Using same approach, we analyzed the correlation between TERT, TERC, and AGO2 mRNA expression in various cancers based on The Cancer Genome Atlas (TCGA) data from OncoLnc and cBioPortal. Expression data were downloaded from TCGA's data portal (https://tcga-data.nci. nih.gov/tcga/) on January, 2019 (2). As shown in Figure 1A, TCGA data indicated that AGO2 mRNA expression levels was positively correlated with TERT expression in colon $(\mathrm{r}=0.194, \mathrm{P}<0.001)$, rectal $(\mathrm{r}=0.285, \mathrm{P}<0.001$; Figur $1 B)$, and lung adenocarcinoma $(\mathrm{r}=0.145, \mathrm{P}=0.006)$, breast $(\mathrm{r}=0.205$, $\mathrm{P}<0.001)$ and cervical cancers $(\mathrm{r}=0.192, \mathrm{P}=0.002)$. Laudadio et al. (1) asserted that terc-sRNA is significantly overexpressed in breast cancer and lung adenocarcinoma as compared to normal tissues. Our previous studies demonstrated clinicopathological characteristics of AGO2 in breast and colorectal cancers $(3,4)$. In colorectal cancer, AGO2 expression did not have any clinical significance, however, it appeared down-regulated in breast cancers and was associated with $\mathrm{N}$ stage. This study and our result suggested that AGO2 and telomere associated pathway have an important role in cancers, especially breast and lung cancers.

However, AGO2 mRNA expression levels did not correlated with those of TERC mRNA in any cancers (Figure 1C). As TCGA data provided TERC expression level only in six types of cancers, excluding breast and lung cancers, further study about the correlation between AGO2 and TERC should be performed in these possible cancer types.

Furthermore, the prognostic value of AGO2 mRNA expression was analyzed in various cancers on the basis of TCGA data. AGO2 have a prognostic value in many cancers including bladder $(\mathrm{P}=0.0264)$, head and neck $(\mathrm{P}=0.0287)$, kidney renal papillary cell carcinoma $(\mathrm{P}=0.0005)$, brain $(\mathrm{P}=0.00211)$, liver $(\mathrm{P}=0.0175)$, pancreas $(\mathrm{P}=0.0166)$, and uterine cancers $(\mathrm{P}=0.0175)$. Higher level of AGO2 expression had a poorer prognosis in these cancers, and it is similar with previous reported result (5).

As observed in the current and in previous studies, a positive correlation between AGO2 and TERT mRNA expression in certain cancers suggested that AGO2 probably regulates TERT in an activity-dependent manner with other genetic changes (1). The biological functions of $\mathrm{AGO} 2$ and telomere associated gene are of great interest for further studies in cancer.

\section{Acknowledgments}

Funding: This study was supported by grants of the Basic Science Research Program through the National Research Foundation of Korea (NRF), funded by the Ministry of Education (NRF-2014R1A6A3A04058057) and by the Korean Government (MSIP) (No. 2014R1A5A2010008).

\section{Footnote}

Provenance and Peer Review: This article was a standard submission to the journal. This article has undergone external peer review.

Conflicts of Interest: Both authors have completed the 
A

\begin{tabular}{lcc}
\hline Cancer type & $\mathrm{R}$ & $\mathrm{P}$ \\
\hline Bladder urothelial carcinoma & 0.018 & 0.715 \\
Breast invasive carcinoma & 0.205 & $<0.001$ \\
Cervical squamous cell carcinoma & 0.192 & 0.002 \\
Colon adenocarcinoma & 0.194 & $<0.001$ \\
Esophageal carcinoma & -0.004 & 0.962 \\
Glioblastoma multiforme & 0.003 & 0.972 \\
Head and neck squamous cell carcinoma & -0.049 & 0.275 \\
Acute myeloid leukemia & 0.069 & 0.415 \\
Liver hepatocellular carcinoma & -0.086 & 0.105 \\
Lung adenocarcinoma & 0.145 & 0.006 \\
Lung squamous cell carcinoma & 0.091 & 0.140 \\
Ovarian serous cystadenocarcinoma & 0.081 & 0.166 \\
Pancreatic adenocarcinoma & 0.104 & 0.172 \\
Rectum adenocarcinoma & 0.285 & $<0.001$ \\
Skin cutaneous melanoma & 0.049 & 0.301 \\
Stomach adenocarcinoma & 0.037 & 0.480 \\
Uterine corpus endometrial carcinoma & 0.019 & 0.653 \\
\hline
\end{tabular}

B



Figure 1 TCGA data analysis for the correlation between AGO2, TERT, and TERC in various cancers. (A) Correlation between AGO2 and TERT; (B) representative graph of the correlation between AGO2 and TERT; (C) correlation between AGO2 and TERC.

ICMJE uniform disclosure form (available at http://dx.doi. org/10.21037/tcr.2019.09.41). JHL serves as the unpaid editorial board member of Translational Cancer Research from Nov 2018 to Oct 2020. The other author has no conflicts of interest to declare.

Ethical Statement: The authors are accountable for all aspects of the work in ensuring that questions related to the accuracy or integrity of any part of the work are appropriately investigated and resolved.

Open Access Statement: This is an Open Access article distributed in accordance with the Creative Commons Attribution-NonCommercial-NoDerivs 4.0 International License (CC BY-NC-ND 4.0), which permits the noncommercial replication and distribution of the article with the strict proviso that no changes or edits are made and the original work is properly cited (including links to both the formal publication through the relevant DOI and the license). See: https://creativecommons.org/licenses/by-nc-nd/4.0/.

\section{References}

1. Laudadio I, Orso F, Azzalin G, et al. AGO2 promotes telomerase activity and interaction between the telomerase components TERT and TERC. EMBO Rep 2019. doi: 10.15252/embr.201845969.

2. Anaya J. OncoLnc: linking TCGA survival data to mRNAs, miRNAs, and lncRNAs. Peer J Comp Sci 2016;2:e67.

3. Kim B, Lee JH, Park JW, et al. An essential microRNA maturing microprocessor complex component DGCR8 is up-regulated in colorectal carcinomas. Clin Exp Med 2014;14:331-6.

4. Kwon SY, Lee JH, Kim B, et al. Complexity in regulation of microRNA machinery components in invasive breast carcinoma. Pathol Oncol Res 2014;20:697-705.

5. Zhang $\mathrm{H}$, Wang $\mathrm{Y}$, Dou J, et al. Acetylation of AGO2 promotes cancer progression by increasing oncogenic miR-19b biogenesis. Oncogene 2019;38:1410-31.

Cite this article as: Jung SJ, Lee JH. Analysis of The Cancer Genome Atlas data to determine the correlation between AGO2, TERT, and TERC in various cancers. Transl Cancer Res 2019;8(6):2504-2505. doi: 10.21037/tcr.2019.09.41 